\section{Referenties}

Ali R, Elsayed M, Kaur M et al. Use of social media to assess the effectiveness of vagal nerve stimulation in Dravet syndrome: A caregiver's perspective. Journal of the Neurological Sciences 2017;375:146-149.

Dibué-Adjeia M, Fischer I, Steiger HJ et al. Efficacy of adjunctive vagus nerve stimulation in patients with Dravet syndrome: A meta-analysis of 68 patients. Seizure 2017;50:147-152.

George R, Sonnen A, Upton A et al. The vagus nerve stimulation study group. A randomized controlled trial of chronic vagus nerve stimulation for treatment of medically intractable seizures. Neurology 1995;45:224-230.

Hamilton P, Soryal I, Dhahri P et al. Clinical outcomes of
VNS therapy with AspireSRI (including cardiac-based seizure detection) at a large complex epilepsy and surgery centre. Seizure 2018;58:120-126.

Handforth A, DeGiorgio CM, Schachter SC et al. Vagus nerve stimulation therapy for partial-onset seizures. A randomized active-control trial. Neurology 1998;51:48-55. Klinkenberg S, Aalbers MW, Vles JSH et al. Vagus nerve stimulation in children with intractable epilepsy: a $\mathrm{r}$ andomized controlled trial. Dev Med Child Neurol 2012;54:855-61.

Serdaroglu A, Arhan E, Kurt G et al. Long term effect of vagus nerve stimulation in pediatric intractable epilepsy: an extended follow-up. Childs Nerv Syst 2016;32:641-646.

\title{
Hoe minder toezicht, hoe groter de kans op SUDEP
}

SUDEP - Sudden unexpected death in epilepsy - is de meest voorkomende epilepsie-gerelateerde doodsoorzaak. Inmiddels zijn er verschillende risicofactoren voor het optreden van SUDEP vastgesteld, waarvan het hebben van (nachtelijke) tonisch-clonische aanvallen de grootste risicofactor is. In het onderzoek dat hier wordt beschreven stond de vraag centraal of het intensiveren van nachtelijk toezicht in woonzorginstellingen het SUDEP-risico verlaagt.

Er zijn aanwijzingen dat circadiaanse factoren van invloed zijn op SUDEP: (I) SUDEP is meestal slaap-gerelateerd, (2) het risico op SUDEP is hoger wanneer iemand nachtelijke tonisch-clonische aanvallen heeft (Lamberts et al., 20I2). Verder lijkt toezicht ook een rol te spelen: SUDEP treedt vaker op als iemand alleen is (Lamberts et al., 2012, Langan et al., 2005). Een recente Cochrane-review geeft echter aan dat er very limited and low quality evidence is dat nachtelijk toezicht het risico op SUDEP zou kunnen verkleinen (Maquire et al., 2016). Dit is een dilemma voor woonzorginstellingen voor mensen met epilepsie en een verstande- lijke beperking. In deze populatie is de SUDEP-incidentie namelijk aanzienlijk (Klenerman et al., I993; McKee et al., 2000). Een recente audit bij de Stichting Epilepsie Instellingen Nederland (SEIN) toonde aan dat met het gebruik van een akoestisch waaksysteem zonder videomonitoring een derde van de nachtelijke aanvallen werd gemist (van der Lende et al., 20I6). In dit vervolgonderzoek werd nagegaan wat de SUDEP-incidentie is in woonzorginstellingen en wat het effect is van nachtelijk toezicht op het SUDEP-risico (van der Lende et al., 20I8).

\begin{tabular}{|c|l|}
\hline Graad I & Geen akoestisch waaksysteem EN slaapt alleen EN geen fysieke controles elke I5 minuten \\
\hline Graad 2 & $\begin{array}{l}\text { Akoestisch waaksysteem } \\
\text { Kamergenoot } \\
\text { Ten minste elke I5 minuten fysiek een controle }\end{array}$ \\
\hline Graad 3 & $\begin{array}{l}\text { Akoestisch waaksysteem EN kamergenoot } \\
\text { Akoestisch waaksysteem EN aanvullend systeem (matrassensor / videomonitoring) } \\
\text { Akoestisch waaksysteem EN fysiek een controle elke I5 minuten }\end{array}$ \\
\hline
\end{tabular}

Tabel 1 Gradering van nachtelijk toezicht 

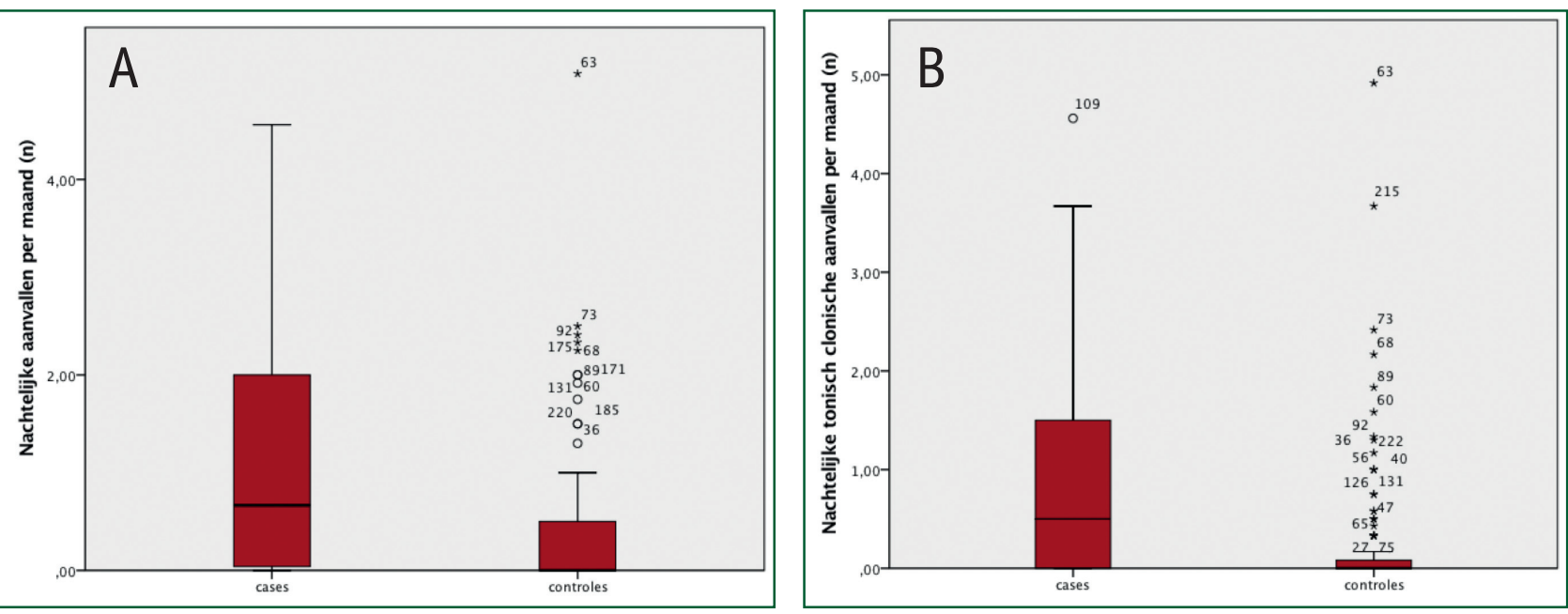

Figuur 1 Weergave van aantal nachtelijke aanvallen (A) en nachtelijke tonisch-clonische aanvallen (B) per maand bij de SUDEP-cases (linkerkolom) en de controles (rechterkolom).

\section{Methode}

Er werd een case-control-onderzoek gedaan, waarbij de status en het obductieverslag werden bestudeerd van alle mensen die in de afgelopen 25 jaar zijn overleden in twee woonzorginstellingen voor mensen met epilepsie en een verstandelijke beperking: SEIN, locatie de Cruquiushoeve en Chalfont Centre for Epilepsy, Chalfont St Peter, Verenigd Koninkrijk. In SEIN werden alle overlijdens op de woonzorgafdelingen van 1987 tot 2012 geanalyseerd; in Chalfont Centre for Epilepsy alle overlijdens van I989 tot 20I4. Alle mensen die overleden aan 'definite SUDEP' (obductie gedaan) of 'probable SUDEP' (voldoet aan alle SUDEP-criteria, alleen geen obductie gedaan) werden geselecteerd. Overlijdens van mensen ouder dan 60 jaar zijn geëxcludeerd in verband met een hoger risico op andere doodsoorzaken. Per casus werden vier controles geselecteerd: die in hetzelfde gebouw woonden en van dezelfde leeftijd waren $( \pm$ vijf jaar) op het moment dat de case overleed.

\section{Nachtelijk toezicht}

Tot eind jaren negentig van de vorige eeuw hadden beide woonzorgcentra vooral twee- en vierpersoonskamers. Vanaf 2000 veranderde dit in beide centra en werden er uitsluitend eenpersoonskamers aangeboden. In 1999 is in alle woongebouwen van SEIN een akoestisch waaksysteem geïnstalleerd. Later werden ook extra maatregelen getroffen voor mensen met een verdenking op gemiste nachtelijke aanvallen: matrassensoren vanaf 2008 en videomonitoring vanaf 20I0. Om alle apparatuur te monitoren is er in de nacht één verzorgende per veertien cliënten aanwezig. Deze verzorgenden doen ook minstens één of twee keer per nacht fysiek een controle.

In het Chalfont Centre for Epilepsy is er geen centraal akoestisch waaksysteem. In enkele gevallen werden babyfoons of valmatten gebruikt. In de loop der jaren is de inzet van het nachtelijke personeel wel gestegen: van één verzorgen- de per twaalf cliënten naar één verzorgende per zes cliënten. Volgens protocol worden alle patiënten eens per I5 of eens per 30 minuten gecontroleerd. Nachtelijk toezicht werd geclassificeerd in drie categorieën (tabel I). Een analyse van de video-EEG-registraties van SUDEP-overlijdens toonde aan dat terminale apneu binnen II minuten na het einde van de aanval optreedt (Ryvlin et al., 2013). Om deze reden werd het fysiek uitvoeren van een controle alleen aangemerkt als een extra maatregel als deze elke i5 minuten plaatsvond.

\section{Resultaten}

Er werden 6o SUDEP-cases geïdentificeerd, die gematcht werden met 198 controles. Mensen die overleden aan SUDEP hadden vaker nachtelijke tonisch-clonische aanvallen ( $77 \%$ van de cases versus $33 \%$ van de controles, $\mathrm{p}<0.00 \mathrm{I}$ ) en een hogere frequentie van nachtelijke tonisch-clonische aanvallen (figuur I).

De totale SUDEP-incidentie was 3,53/I.0oo persoonsjaren (95\% betrouwbaarheidsinterval 2,73-4,53). De incidentiecijfers van beide centra waren significant verschillend: 2,2I/I.00o persoonsjaren ( $95 \%$ betrouwbaarheidsinterval $\mathrm{I}, 49-3,27)$ in SEIN versus 6,I2/I.00o persoonsjaren (95\% betrouwbaarheidsinterval $4,40-8,52$ ) in Chalfont.

Het nachtelijk toezicht verschilde niet significant tussen de cases en controles. Tussen de verschillende centra verschilde het nachtelijk toezicht echter wel: het centrum met de laagste graad van nachtelijk toezicht had de hoogste SUDEP-incidentie (figuur 2).

\section{Conclusie en implicaties voor de praktijk}

In de twee woonzorgcentra voor mensen met epilepsie en een verstandelijke beperking verhoogde de aanwezigheid en frequentie van tonisch-clonische aanvallen het SUDEPrisico. De SUDEP-incidentie verschilde significant tussen beide centra. Dit kon niet worden verklaard door markers 
voor de ernst van de epilepsie. Daarentegen werd er wel een significant verschil gezien in de mate van toezicht: het centrum met het minste toezicht had de hoogste SUDEP-incidentie.

Het nachtelijk toezicht was significant verschillend tussen de twee centra, maar verschilde niet tussen de cases en controles binnen eenzelfde centrum. Dit komt waarschijnlijk omdat de controles van een casus uit hetzelfde centrum kwamen. De meeste aanvalsdetectiesystemen zijn geïmplementeerd per woongebouw. Cases en controles kwamen uit hetzelfde woongebouw, wat resulteerde in geen significant verschil tussen en cases en controles binnen één centrum.

Om het verschil in SUDEP-incidentie tussen centra te verklaren werden bekende SUDEP-risicofactoren zoals de aanwezigheid en frequentie van tonisch-clonische aanvallen, die zowel overdag als 's nachts optraden, vergeleken tussen de cases van de twee centra. Deze verschilden niet. Het enige wat verschilde tussen de cases van de verschillende centra was het nachtelijk toezicht. Dit lijkt ook de enige logische verklaring voor het verschil in SUDEPincidentie tussen de centra.

\section{Onderzoek naar SUDEP:}

\section{overeenkomsten en verschillen}

In het onderzoek naar de relatie tussen nachtelijk toezicht in woonzorginstellingen en het SUDEP-risico werd niet bij alle cases obductie gedaan, terwijl er een SUDEPpuntenscore werd ontwikkeld aan de hand van de klinische data van de mensen bij wie wel een obductie beschikbaar was (van der Lende et al., 2018). Er werden alleen SUDEP-cases ouder dan 6o jaar geïncludeerd, om misclassificatie van probable SUDEP en een diagnostische bias te voorkomen. Bovendien werden alleen de belangrijkste SUDEP-risicofactoren vergeleken tussen de centra. Echter, de impact van andere factoren zo-als een verschillend medicatiebeleid moet ook worden overwogen. De aanvalsfrequenties tussen de centra waren echter niet verschillend, wat suggereert dat dit geen grote factor was.

Het onderzoek van Van der Lende et al. (2018) bevestigt de welbekende risicofactoren zoals het hebben van tonischclonische aanvallen en een hoge frequentie hiervan (Maquire et al., 20I6). Er werd ook bevestigd dat de aanwezigheid en frequentie van nachtelijke tonisch-clonische aanvallen een onafhankelijke risicofactor is (Lamberts et al., 20I2). De sterke relatie tussen SUDEP en slaap wordt vermoedelijk verklaard door de interactie met twee omgevingsfactoren: buikligging en de afwezigheid van iemand die eventueel kan ingrijpen. De meeste SUDEP-slachtoffers worden liggend op de buik aangetroffen. Buikligging zou op zichzelf geen problemen moeten geven voor de ademhaling: als die geblokkeerd rakt zou dit normaal gesproken een arousal veroorzaken. Dit ligt waarschijnlijk anders

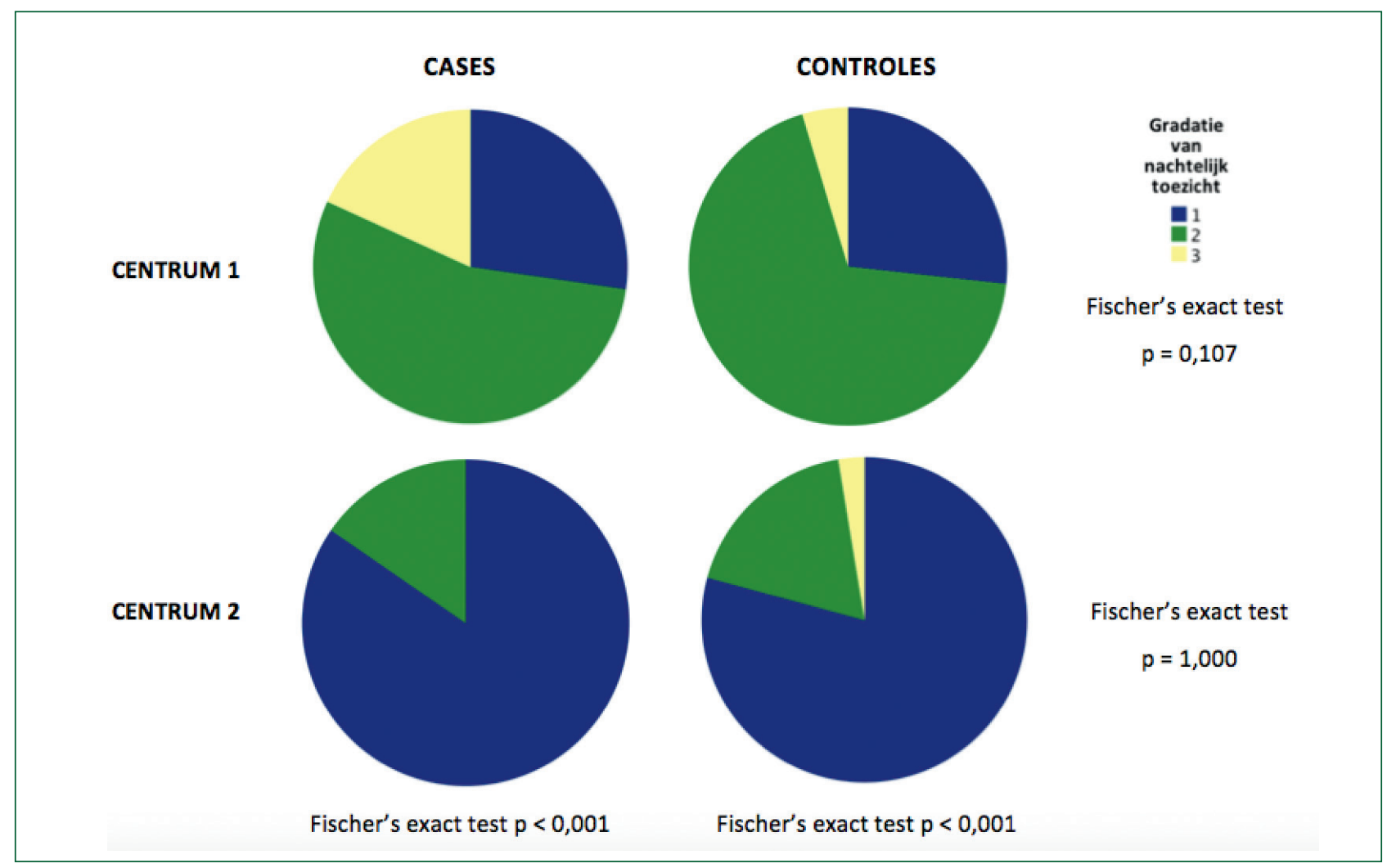

Figuur 2 Vergelijking van mate van nachtelijk toezicht tussen de cases en controles van centrum 1 en 2 in percentages. De cases en de controles van het centrum met de meeste SUDEP-gevallen (centrum 2) hadden een lagere graad van nachtelijk toezicht (beide p < 0,001). 
bij iemand met een postictaal coma: die wekprikkel treedt vermoedelijk dan niet op. In die context is het wel denkbaar dat de buikligging ervoor kan zorgen dat er een apneu en uiteindelijk SUDEP optreedt. Interventies zoals het herpositioneren (leggen in de stabiele zijligging) of wellicht het toedienen van zuurstof zou de respiratoire dysfunctie na convulsieve aanvallen kunnen verkorten. Het is van groot belang dat er meer duidelijkheid komt welke interventies in de postictale fase nodig zijn om SUDEP te voorkomen.

Nachtelijk toezicht verlaagt het SUDEP-risico. Uit een case-control-studie bleek dat SUDEP-cases vergeleken met controles vaker geen kamergenoot hadden en geen akoestisch waaksysteem (Langan et al., 2005). In een cohortonderzoek in een internaat voor kinderen met ernstige epilepsie en verstandelijke beperking kwamen alle SUDEPoverlijdens voor op het moment dat de kinderen niet onder de supervisie van de school waren (Nashef et al., I995). Gezien het retrospectieve karakter van deze onderzoeken en van het onderzoek van van der Lende et al. (2018) is het niet mogelijk om te bepalen welke stappen precies gezet moeten worden om het toezicht te verbeteren. Hiervoor was de praktijkvariatie in de onderzoeken te groot.

\section{Conclusie}

Het contrast in nachtelijk toezicht tussen beide centra lijkt grotendeels verklaard te worden door de implementatie van een akoestisch waaksysteem in een van de centra. Uitluisteren is een eerste belangrijke stap, aangezien tonisch-clonische aanvallen vaak gepaard gaan met een ictale kreet. Wanneer een akoestisch waaksysteem niet afdoende was, werden aanvullende systemen gebruikt in centrum I, zoals matrassensoren en video-monitoring, ingesteld op het individu. Dit betrof slechts een kleine subgroep en zal daarom weinig invloed hebben gehad op de SUDEPincidentie. Het onderzoek van Van der Lende et al. (2018) onderstreept hiermee opnieuw het belang van betrouwbare aanvalsdetectie systemen bij mensen met een hoog SUDEP-risico.

\section{Referenties}

Klenerman P, Sander JW, Shorvon SD (I993) Mortality in patients with epilepsy: a study of patients in long term residential care. Journal of neurology, neurosurgery, and psychiatry 56:149-152.

Maguire MJ, Jackson CF, Marson AG et al. (20I6) Treatments for the prevention of Sudden Unexpected Death in Epilepsy (SUDEP). The Cochrane database of systematic reviews 7:CD011792.

McKee JR, Bodfish JW (2000) Sudden unexpected death in epilepsy in adults with mental retardation. American journal of mental retardation: AJMR 105:229-235.

Lamberts RJ, Thijs RD, Laffan A et al. (20I2) Sudden unexpected death in epilepsy: people with nocturnal seizures may be at highest risk. Epilepsia 53:253-257.

Langan Y, Nashef L, Sander JW (2005) Case-control study of SUDEP. Neurology 64:1131-1133.

van der Lende M, Cox FM, Visser GH et al. (2016) Value of video monitoring for nocturnal seizure detection in a residential setting. Epilepsia 57:1748-1753.

van der Lende M, Hesdorffer DC, Sander JW et al. (2018)

Nocturnal supervision and SUDEP risk at different epilepsy care settings. Neurology 91:eI508-eI518.

Nashef L, Fish DR, Garner S, Sander JW, Shorvon SD

(I995) Sudden death in epilepsy: a study of incidence in a young cohort with epilepsy and learning difficulty. Epilepsia 36:1187-1194.

Ryvlin P, Nashef L, Lhatoo SD et al. (2013) Incidence and mechanisms of cardiorespiratory arrests in epilepsy monitoring units (MORTEMUS): a retrospective study. The Lancet Neurology 12:966-977.

\title{
Hebt u de website van het Epilepsiefonds al bekeken?
}

\author{
www.epilepsie.nl
}

